\title{
Juventude e política: Cenários de visibilidade e invisibilidade
}

As práticas juvenis contemporâneas têm produzido estranhamentos, uma vez que seus modos de sentir e agir não se mostram consoantes com os conhecidos. Vários desses modos tensionam o regime institucional vigente e, ao tensioná-lo, podem propiciar novas esferas de luta, visibilidade e enfrentamento na direção de seus direitos. Que formas de objetivação na esfera política tem se feito visíveis e audíveis para a sociedade mais ampla? Discutir a participação política e social da juventude implica por em debate a visão da sociedade, de seus conflitos, da própria noção de política, assim como das crenças que sustentamos sobre as instituições e seu modo de funcionamento.

Em outubro de 2011, o Programa de Pós-Graduação em Psicologia da Universidade Federal de Santa Catarina, por meio do Núcleo de Pesquisas em Práticas Sociais: "relações éticas, estéticas e processos de criação" e com o apoio do Conselho Nacional de Desenvolvimento Científico e Tecnológico (CNPq) do Ministério de Ciência e Tecnologia do Brasil, realizou, na Universidade Federal de Santa Catarina, o II Seminário Internacional de Juventude e Política e o V Internúcleos sobre Juventude e Política. O evento reuniu um grupo de pesquisadores nacionais e estrangeiros para a troca e o aprofundamento de discussões acerca da participação política e social dos jovens no mundo contemporâneo, culminando no dossiê que ora se apresenta.

Encontros anteriores foram realizados no Rio de Janeiro em 2007 (I Internúcleos Juventude e Política), em Belo Horizonte em 2008 (II Internúcleos Juventude e Política), em Recife em 2009 (III Internúcleos Juventude e Política) e no Rio de Janeiro em 2010 (Seminário Latinoamericano de Juventude e Política e IV Internúcleos Juventude e Política). Ao longo desses anos e com a experiência desses encontros foi-se constituindo um grupo de investigadores que tem interesses convergentes e desejam dialogar sobre os diversos problemas e questões que emergem no âmbito do campo de pesquisas sobre juventude e política. O grupo de pesquisadores é composto por docentes, alunos de pós-graduação e graduação das Universidades Federais do Rio de Janeiro (UFRJ), Minas Gerais (UFMG), Pernambuco (UFPE), Santa Catarina (UFSC), Alagoas (UFAL), Universidade Estadual do Rio de Janeiro (UERJ) e da Pontifícia Universidade Católica de Minas Gerais (PUC-Minas).

Esse grupo de investigadores, coordenado pela Profa. Dra. Lúcia Rabello de Castro (UFRJ), foi construindo estudos específicos e produziu parcerias que se objetivaram na formalização de um projeto nacional de pesquisa intitulado $A$ Participação Social Juvenil: subjetividade, cultura, politica e direitos, aprovado pelo Conselho Nacional de Desenvolvimento Científico e Tecnológico (CNPq) do Ministério de Ciência e Tecnologia do Brasil, em agosto de 2009. O resultado desta investigação interinstitucional consolidou-se na produção de um livro, intitulado Juventude e a experiência da política no contemporâneo $^{1 *}$, organizado por Cláudia Mayorga, Lúcia Rabello de Castro e Marco Aurélio Máximo Prado.

$\mathrm{O}$ dossiê que aqui apresentamos se constitui na continuidade desse trabalho e congrega investigações da equipe do projeto, produtos do encontro realizado na Universidade Federal de Santa Catarina. São textos que apresentam discussões variadas, cujas linhas de investigação, em que pesem diferenças e singularidades, apresentam pontos comuns para reflexão e aprofundamento. Objetiva-se com esse dossiê delinear pontos de aproximação, equivalência e distanciamento nas pesquisas sobre juventude e política, em termos de temas e problemas pesquisados, questões teóricas emergentes, questões metodológicas recorrentes, impacto nas políticas públicas, aspectos transdisciplinares e outros.

Com a publicação deste dossiê esperamos, sobretudo, provocar o olhar de colegas com experiência diversa e que possam contribuir para prover nuances e complexidade ao debate e ao pensamento em torno do campo da participação política da juventude hoje.

Agradecemos imensamente a equipe editorial da revista Estudos de Psicologia (Natal), em especial, a Isabel Fernandes que foi editora em 2011 e acolheu esta proposta, e as editoras Katie Almondes e Fívia Lopes, pelo apoio, disponibilidade e efetivo suporte desde os procedimentos iniciais até a finalização deste trabalho.

Desejamos a todos uma excelente leitura.

\section{Kátia Maheirie Andréa Vieira Zanella Universidade Federal de Santa Catarina}

\footnotetext{
* Mayorga, C.; Castro, L. R. de; Prado, M. A. M. (2012). Juventude e a experiência da política no contemporâneo. Rio de Janeiro: Ed. Contra Capa.
} 